\section{CAUSAL FACTORS IN SCHIZOPHRENIA}

The Biology of Schizophrenia

By Dr. R. G. Hoskins. Pp. 192. (New York: W. W. Norton and Co., Inc.; London : Chapman and Hall, Ltd., 1946.) 15s. net.

$\mathrm{T}$ $\mathrm{HE}$ greatest problem of modern psychiatry is that of schizophrenia. The vast majority of the permanent occupants of the mental hospital consists of patients suffering from this disease, which besides cripples a large number of patients who contrive to live a precarious existence in the outside world as tramps, eccentrics, prostitutes and similar misfits.

Dr. Hoskins' book is a valuable review of this psychosis. It is an expanded version of his three Salmon Lectures. The first part is devoted to a description of the development of human personality and social community on the basis of emergent evolution. The second part is a description of schizophrenia as a pattern and the comparison of it with various biological reactions found in other animals. It is the third part which will be of most interest to the clinical psychiatrist and the research worker. In this part he reviews a large amount of modern literature and examines the various possible causes for the curious symptoms which characterize this disease. He examines the endocrine factors, the oxygen relationships, the carbohydrate metabolism, the circulatory conditions and the importance of hæmostasis. Many of the facts which Dr. Hoskins discusses here have been determ. ined by his own research team at Worcester' State Hospital.

It is obvious that in research upon an obscure disease process such as schizophrenia there is no one method of approach; but it is rather the correlation of the multitudinous minor discoveries which will give the final clue. Dr. Hoskins wisely takes the biological stand and attempts to fit together what is known; but unfortunately not snough has yet been discovered to make it possible to solve the problem. $\mathrm{He}$ seems to think that the avenues of research tend to lead towards the problem of maturation as related to the endocrines, vitamins and enzymes. He points out that the schizophrenic is lacking in empathy (the basis of emotional relations with others), and that if we could discover the cause of this deficiency we should be advancing our chances of solving the whole problem. In this matter he points out that feral children - children who have been adopted by wild animals since an early age-are totally lacking in power to show empathy. He suggests the importance of inheritance by quoting the well-known work on twins, in which it was shown that if one of monozygotic twins developed schizophrenia this also tended to appear in the other, while dizygotic twins did not show similar reactions.

Dr. Hoskins shows an easy tolerance to all schools of psychiatry and writes fairly and generously from all points of view. His style is clear and understand. able-a virtue not always found in psychological books. The format itself is excellent, the print is clear, with wide margins such as have not been seen in Britain since the paper shortage. The binding is good. There is a long list of references, which are valuable to those who wish to read one particular part of the literature, and there is an excellent index.
A BIRD PHOTOGRAPHER ABROAD

\section{Bird Life in Two Deltas}

Being the Diaries of a Bird Photographer in the Estuaries of the Guadalquiver and the Rhone and their Neighbourhoods. By G. K. Yeates. Pp. 159+ 68 plates. (London: Faber and Faber, Ltd., 1946.) 15s. net.

THE standard of bird photography has risen high in recent years, but we have no better exponent of the art, for an art it has become, than G. K. Yeates. His bird portraits are superb examples of the work of the camera. In his latest book, "Bird Life in Two Deltas", we see pictures taken in Spain and in the south of France. "The Spanish marismas at the estuary of the great Guadalquiver and the Camargue or Rhône-Delta constitute two of the greatest bird paradises in Western Europe", says the author. He goes on, "The brief visits of a foreigner to these great oases of bird-life, so vast that even a lifetime would leave much unseen and unexplored, can in themselves provide only a fleeting glimpse into the wealth and variety of their natural history. These three diaries which follow are the unadorned records of my visits."

But the diaries, if 'unadorned', are not the less interesting for that, for they tell a plain story very well, the story of a naturalist in a rich field, of his difficulties, his triumphs and his many observations. Here is his account of flamingoes: "Never have I been so moved by the sheer wondrous beauty of a bird as I was today by these flamingoes. . . W W first saw the birds as a long thin pink line through the mirage. As we came closer, they assumed more definite shape. When wading through the shallows, the flamingoes' general colour scheme is a very soft pink. The body appears like a round ball precariously balanced on two long pink stilts. The long thin serpentine neck with the curious heavy downwardtilted bill completes a strange picture. . . . The soft reflections of the long thin pale-pink line in water that took its colour from the blue of the sky defeat my poor pen for description."

Yeates adds: "Lovely as is the flamingo as it wades, it is a flash of glory on the wing, for then instead of the soft pinks which predominate on the ground the bird exposes the brilliant scarlet of the covert feathers . . nor is it just one bird in the air. Numbers on such a scale are difficult to estimate, but I do not think 1,500 far short of the birds that were here present."

Buff-backed herons, little egrets, black-winged stilts, night herons, hoopoes, etc., provide the author with many observations on bird behaviour and with photographs of remarkable quality.

Of special interest are his records of the penduline tit in the act of constructing its nest. Photographs of nest-building are rare. This species contrives a lovely little domed nest after the style of that of the familiar long-tailed tit, but uses reed 'down' instead of moss and lichen. A favourite site is among the drooping sprays of tamarisk. We here see stages in the building, an outer circle or hoop being first con. structed, in which the bird works and builds up the main walls.

Several useful appendixes are to be found at the end of the book-a bibliography which will be helpful to anyone desiring to look up the literature of these bird paradises, a list of scientific names and a list of the French names of the Camargue birds. 